BMJ Open

Sport \&

Exercise

Medicine

\section{Effects of exercise training on physical and psychosocial health in children with chronic respiratory disease: a systematic review and meta-analysis}

To cite: Joschtel B,

Gomersall SR, Tweedy S, et al. Effects of exercise training on physical and psychosocial health in children with chronic respiratory disease: a systematic review and meta-analysis. BMJ Open Sport \& Exercise Medicine 2018;0:e000409. doi:10.1136/ bmjsem-2018-000409

- Additional material is published online only. To view please visit the journal online (http://dx.doi.org/10.1136/ bmjsem-2018-000409).

Accepted 29 August 2018

Check for updates

\section{(C) Author(s) (or their} employer(s)) 2018. Re-use permitted under CC BY-NC. No commercial re-use. See rights and permissions. Published by BMJ.

For numbered affiliations see end of article.

\section{Correspondence to} Dr Stewart G Trost; s.trost@qut. edu.au

\author{
Barbara Joschtel, ${ }^{1}$ Sjaan R Gomersall, ${ }^{2}$ Sean Tweedy, ${ }^{1}$ Helen Petsky, ${ }^{3}$ \\ Anne B Chang, ${ }^{4,5,6}$ Stewart G Trost ${ }^{5}$
}

\section{ABSTRACT}

Introduction Chronic disease in children is increasing, including the prevalence of chronic respiratory diseases such as asthma, cystic fibrosis (CF), bronchiectasis and bronchopulmonary dysplasia (BPD). The aim of this systematic review and meta-analysis was to evaluate the effects of exercise training on health outcomes in children with chronic respiratory disease.

Method Five databases were searched for randomised controlled trials investigating the effects of exercise training on children with chronic respiratory disease. Following the PRISMA guidelines, eligible studies were identified and data were extracted. A meta-analysis was conducted for the outcomes cardiovascular fitness, lung function and quality of life (QoL).

Results The initial search returned 3688 papers. Twentyseven (17 in children with asthma, 10 in children with CF) were included in the systematic review and 24 of these were included in the meta-analysis. No studies were identified in children with bronchiectasis or BPD. Included papers had a total of 1009 participants aged 8-20 years. In addition to cardiovascular fitness, lung function and QoL, studies also assessed pulmonary function, respiratory muscle strength, muscular strength and inflammation. Meta-analysis showed a large significant effect size in favour of exercise for cardiovascular fitness (peak $\mathrm{VO}_{2}$ ) (standard mean difference $(\mathrm{SMD})=1.16,95 \% \mathrm{Cl} 0.61$ to 1.70) and QoL (SMD=1.27, $95 \% \mathrm{Cl} 0.72$ to 1.82 ) as well as a small, non-significant effect size for lung function ( $\mathrm{FEV}_{1}$ ) (SMD $=0.02,95 \% \mathrm{Cl}-0.38$ to 0.42 ).

Conclusion Exercise training significantly improves cardiovascular fitness and QoL in children with asthma and CF. Further research is needed, particularly in children with bronchiectasis and BPD.

\section{INTRODUCTION}

Chronic disease is defined as long-lasting illness that has a persistent effect on health and quality of life (QoL). ${ }^{1}$ The WHO estimates that, worldwide, 38 million people die every year because of a non-communicable disease and this number is expected to increase to 52 million people by $2030 .^{2}$ Coincident with this increase, there has been a

\section{What is already known}

- Exercise has been shown to be beneficial for healthy children by improving cardiovascular fitness, musculoskeletal health, mental health and elements of cardiometabolic risk factors.

- Exercise improves cardiovascular fitness and quality of life (QoL) in children with asthma and cystic fibrosis (CF). The effect of exercise on lung function in children is still controversial.

What are the new findings

There are no published studies investigating the effect of exercise training in children with bronchiectasis and bronchopulmonary dysplasia.

- Exercise has a different effect on QoL and cardiovascular fitness in children with asthma and CF.

global increase in the prevalence of chronic health conditions among children and adolescents. For example, between 1988 and 2006, the prevalence of chronic disease among children and youth in the USA increased from $12.6 \%$ to $26.6 \%,{ }^{3}$ and it is estimated that by 2020, non-communicable disease will be one of the leading causes of illness, disability and death among young people. ${ }^{4}$ In Australia, just over $66 \%$ of children and adolescents aged 15 years or younger suffer from a chronic health condition. ${ }^{5}$ Chronic disease is associated with ill health, disability and death and with significant personal, social and economic impacts. ${ }^{1}$

One of the major groups of chronic health conditions in children and adolescents is respiratory disease. Chronic respiratory diseases are a diverse group of disorders affecting the lungs and respiratory system. ${ }^{67}$ In children, these conditions include asthma, cystic fibrosis (CF), bronchiectasis, consequences of chronic neonatal lung disease

BA $\stackrel{\text { 包 }}{\text { sem }} 1$


or bronchopulmonary dysplasia (BPD), sleep apnoea and interstitial lung disease. ${ }^{18}$ Asthma, a heterogeneous condition consisting of reversible airway obstruction, airway inflammation and increased airway responsiveness, is the most common respiratory disease, affecting approximately 16 million children worldwide. ${ }^{679} \mathrm{CF}$ is an autosomal recessive disease and is the most common inherited life-limiting illness in children. For $95 \%$ people with CF, the cause of mortality will be respiratory failure. ${ }^{6}$ Bronchiectasis is characterised by irreversible dilatation of one or more bronchi and decreased lung function ${ }^{10}$ and is a major contributor to respiratory morbidity, especially among socially and economically disadvantaged groups. Worldwide, there are more people with bronchiectasis than $\mathrm{CF}^{6}{ }^{11}$ The modern and the most widely used definition defines BPD as oxygen dependence at 36 weeks of postmenstrual age (gestational age plus chronological age). It is related to damage of the undeveloped lung tissues of babies born prematurely. Children with BPD as infants have a greater risk of respiratory symptoms such as coughing, wheezing and asthma than children who did not suffer from BPD after birth. ${ }^{12}{ }^{13}$ These respiratory conditions are associated with poorer QoL, lung function and exercise tolerance.

Among healthy children, there is consistent evidence that exercise confers numerous health benefits such as improved cardiovascular fitness, musculoskeletal health, mental health and elements of cardiometabolic risk factors such as reduced adiposity, blood lipids, blood sugar levels and blood pressure. ${ }^{415}$ Among children with respiratory disease, a burgeoning evidence base suggests that regular exercise improves cardiovascular fitness and QoL. ${ }^{16}$ Nevertheless, the type, frequency, intensity and duration of exercise required for health benefits remains understudied and poorly understood.

To date, a number of systematic reviews have examined the effects of exercise training in children with asthma or $\mathrm{CF}^{17-21}$ Their results indicate that exercise training improves cardiovascular fitness; however, there was no consensus on the effects of exercise on lung function or QoL. Two recently published Cochrane reviews have examined the effects of physical training in people with $\mathrm{CF}^{22}$ or asthma, ${ }^{23}$ but these reviews combined studies involving both children and adults. In a meta-analysis of exercise training studies involving asthmatic children, ${ }^{17}$ swimming training was found to have a positive effect on lung function, with significant changes in forced expiratory volume in one second (FEV1) and forced expiratory flow. Two other reviews in children with asthma concluded that exercise training had a positive impact on peak expiratory flow (PEF) but no effect on $\mathrm{FEV}_{1} \cdot{ }^{18}{ }^{19}$ A review of exercise training in children with $\mathrm{CF}$ on lung function outcomes concluded that exercise improves survival by reducing the rate of decline in lung function. ${ }^{21}$

While these reviews have contributed to our understanding of health benefits of exercise training in children with respiratory disease, important gaps in knowledge remain. First, previous reviews focused on children have only investigated the effects of exercise training in patients with asthma or CF. To our knowledge, no systematic or narrative review has sought to determine the effects of exercise training in children with other respiratory conditions such as bronchiectasis or BPD. Second, previous reviews have focused on a single respiratory condition and not compared the effects of exercise training in different patient groups. Consequently, it is unknown if the effects of exercise are specific to a given respiratory condition or whether it is possible to formulate a single evidence-based exercise guideline for children with respiratory disease. Last but not least, only one of the aforementioned systematic reviews conducted a meta-analysis focused exclusively on paediatric studies. ${ }^{17}$ Combining data from multiple studies can provide a more accurate estimate of the true effects of an intervention, ${ }^{24}$ and in doing so, gain a better understanding of health impacts of exercise training in children with respiratory disease.

To address these gaps, our aim was to undertake a systematic review and meta-analysis of studies to evaluate the effects of exercise training on cardiovascular fitness, lung function and QoL in children with respiratory disease related to asthma, $\mathrm{CF}$, bronchiectasis or BPD.

\section{METHODS}

A search for randomised controlled trials (RCTs) investigating the effects of exercise training in children with respiratory disease was conducted adhering to the guidelines outlined in the Preferred Reporting Items for Systematic Reviews and Meta-analysis (PRISMA) statement. $^{25}$

\section{Search strategy}

The following databases were searched using the following timeframes: PubMed (1951-February 2018), Web of Science (1945-February 2018), CINAHL (Cumulative Index to Nursing and Allied Health Literature) (1982-February 2018), Embase (1988-February 2018) and PsycINFO (1967-February 2018).

The following key words were used and combined with the Boolean phrase 'OR' within groups or 'AND' in between groups:

1. child OR children OR adolescent OR youth OR school age.

2. Chronic respiratory disease OR Chronic pulmonary disease OR Cystic Fibrosis OR cystic fibrosis OR cf OR Mucoviscidosis OR bronchiectasis OR non-cf bronchiectasis OR non-cystic fibrosis bronchiectasis OR bronchopulmonary dysplasia OR asthma OR PCD OR primary ciliary dyskinesia.

3. exercise OR exercise therapy OR physical therapy OR physical intervention OR physical rehabilitation OR pulmonary therapy OR pulmonary intervention OR pulmonary rehabilitation OR respiratory therapy OR respiratory intervention OR respiratory rehabilitation OR rehabilitation OR aerobic OR weight training OR weight lifting OR resistance training OR strength 
training OR running OR run OR walking OR walk OR jogging OR jog OR biking OR bike OR sports OR motor activity OR dancing OR physical activity OR motor skill intervention OR aerobics OR physical activity

4. Intervention OR programme OR training.

We also scanned the references of the retrieved papers for additional studies.

\section{Selection criteria}

Studies had to meet the following criteria to be included:

1. Individual and cluster RCT study design.

2. The study population included had to be children, adolescents or young adults between the ages of 4-21 years, diagnosed with asthma, CF, bronchiectsis, primary ciliary dyskinesia (PCD) or a history of BPD.

3. The study had to report an exercise intervention with a minimum duration of 2 weeks.

4. The study had to report physiological, psychosocial or behavioural outcomes associated with the exercise training intervention.

5. To be included in the meta-analysis the study had to report data from the following outcome measures: peak $\mathrm{VO}_{2}, \mathrm{FEV}_{1} \%$ predicted and QoL.

Studies were excluded if:

1. The study population had a mean age of $\geq 21$ years of age.

2. The study tested interventions other than exercise, for example, pharmacological, psychological or behavioural interventions.

3. They were not written in English.

The initial search results were independently assessed for inclusion eligibility by two of the authors (BJ, ST). Papers were first evaluated by title and abstract and when they were considered eligible, the full text was obtained and evaluated. In the case of disagreement between the two assessors (BJ, ST), the case was discussed between the two assessors until consensus was reached.

\section{Data extraction}

Data were extracted by two of the authors (BJ, ST) from the full text of the final 27 included studies. Data extracted included number of participants and diagnoses, study design, type of intervention, setting of the intervention, outcome measurements, outcomes and effectiveness.

\section{Quality assessment}

The methodological quality of the included studies was assessed using the Physiotherapy Evidence Database Scale (PEDro). The PEDro scale is based on the Delphi list and uses 11 items generating a maximum score of $11 .^{26}$ Each item was assessed for being present $(\boldsymbol{V})$, absent (X) or not applicable (NA). The PEDro scale is commonly used to assess methodological quality of trials. ${ }^{27}$ Methodological quality was independently assessed by two of the authors (BJ, SG).

\section{Meta-analysis}

To be included in the meta-analysis, papers needed to report at least one of the following outcomes: cardiovascular fitness, lung function or QoL. They further needed to report the use of the following outcome measures: peak $\mathrm{VO}_{2}$ as measured by an incremental maximal exercise test; $\mathrm{FEV}_{1} \%$ for lung function and QoL as measured by the Pediatric Asthma Quality of Life Questionnaire (PAQLQ) or Cystic Fibrosis Questionnaire (CFQ). These three outcomes were included due to sufficient numbers of papers reporting the outcome using the same outcome measure, thereby permitting a meta-analysis of the reported data.

Review-Manager (V.5.1 Cochrane Collaboration, Oxford, England) was used for data management and analysis. Change scores and their corresponding SD for the outcomes of interest were extracted from studies to calculate the standardised mean difference (SMD). If change scores were not reported, then the pre and post means of the exercise programme were used to calculate the change scores. SDs were calculated according the Cochrane handbook. ${ }^{24}$ If studies reported medians, SEs or ranges, values were converted into means and SD according to the Cochrane handbook. Due to a large diversity of exercise training parameters (mode, frequency, intensity, duration and time) across all included studies, a randomised effects meta-analysis model was employed. Subgroup analyses were performed for the different patient groups (asthma and CF). For health outcomes positively impacted by exercise training, the relationships between the magnitude of the SMD and the volume, intensity and duration of exercise training were evaluated graphically.

\section{RESULTS}

The PRISMA diagram (figure 1) displays the search findings where 3688 papers were identified via databases and five additional papers identified through other sources. A total of 115 full text publications were screened and 27 articles $^{28-54}$ fulfilled the inclusion criteria. A total of 45 papers were excluded due to study design (not an RCT), 23 papers were excluded because the participant characteristics did not meet the inclusion criteria and 12 papers were excluded because the intervention was not an exercise programme. Five of the excluded papers were reviews and three were letters to a journal and subsequently excluded. Additionally, three papers ${ }^{32} 3411$ were not included in the meta-analysis as they did not report peak $\mathrm{VO}_{2}, \mathrm{FEV}_{1} \%$ or scores on the PAQLQ/CFQ. Therefore, 24 papers ${ }^{28-31} 3335-4042-54$ were included in the meta-analysis.

\section{Study characteristics of included studies}

Asummary of the details of the included studies can be seen in online supplementary digital content 1 . There were 17 studies in children with asthma ${ }^{28-30} 3233353640-4349-54$ and 10 studies in children with CF. ${ }^{313437-3944-48}$ No studies were found in children with bronchiectasis or BPD. Studies were published between 1998 and 2015. Thirteen of those were published between 2000 and 2009 (9 asthma, 
Records identified through data base search $n=3688$
Additional records identified through other sources

$n=5$
Duplicates removed

$$
\mathrm{n}=597
$$

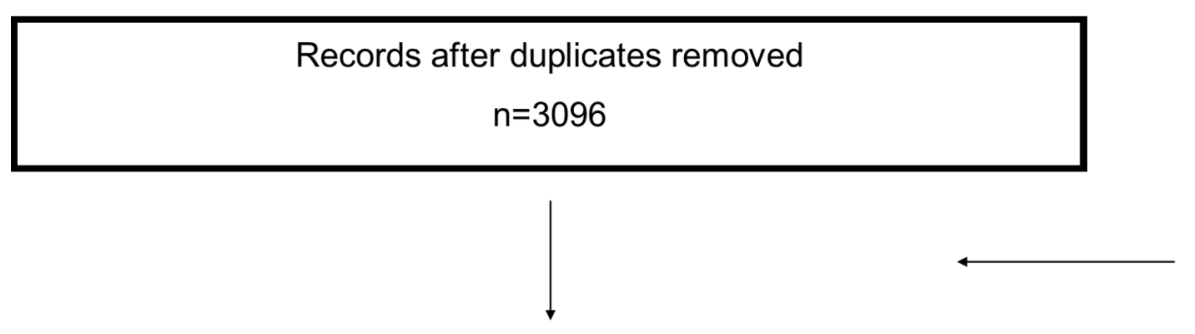

Records excluded on title and abstract

$n=2981$

\section{Full text retrieved}

$n=115$

Studies included in qualitative analysis

$n=27$

Records excluded on full text:

Study design $(n=45)$

Participants $(n=23)$

Intervention $(n=12)$

Reviews ( $n=5)$

\section{Studies included in quantitative analysis}

$n=24$

Figure 1 Results of search strategy of randomised control trials investigating effects of exercise in children with chronic respiratory disease.

3 CF), ${ }^{30} 32-3436394247-4951-53$ and 10 (5 asthma, 5 CF) were published between 2010 and 2015. $2937384043-465054$

The remaining four studies were published before 2000 (three asthma, one CF). ${ }^{28} 313541$ Studies were conducted in 13 different countries, with the majority of studies conducted in Europe (9 asthma, 4 CF) $2830333537394042-455051$ and South America (4 asthma, 3 CF). 29343638464954 The age of the participants ranged between 8 and 20 years. In the asthma studies, age ranged between 8 and 14 years and in CF studies, age ranged between 10 and 20 years. Overall, sample sizes ranged between 8 and 105 participants in asthma and CF, with a median sample size of 34. Only one study had a sample size of over 100 participants. ${ }^{40}$

\section{Quality assessment}

Table 1 provides detailed information about the quality assessment for included studies. Out of the 11 criteria on the PEDro scale, 2 were not applicable because subject and therapist blinding was not possible. Therefore, the highest score achievable was 9 out of 11 points. A score of $\geq 6$ is equivalent to moderate to high quality, ${ }^{27}$ which was found in 18 $293335-4648495152$ of the 27 studies. In asthma and CF, 65\% $2833353640-43495152$ and 70\% ${ }^{37-3944-4648}$ of studies, respectively, achieved a score of $\geq 6$. A score of $\geq 8$ was found in $7^{36384244-4648}$ of the 27 studies. In asthma $12 \%^{3642}$ and in CF $50 \% \%^{3944} 48$ of the studies achieved a score of $\geq 8$. A score of $\leq 5$ was found in $9^{2830-323447505354}$ of the 27 studies. In asthma $35 \% \%^{283032505354}$ and in CF 


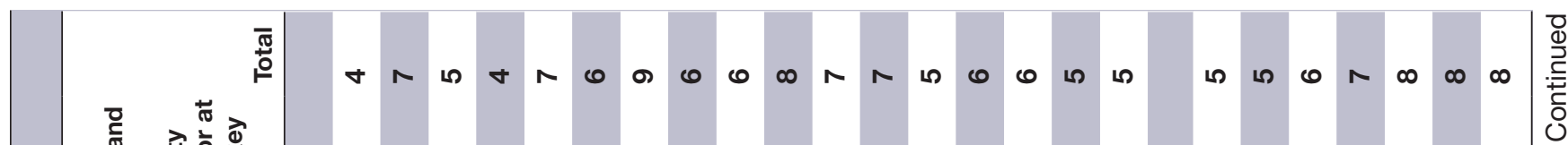




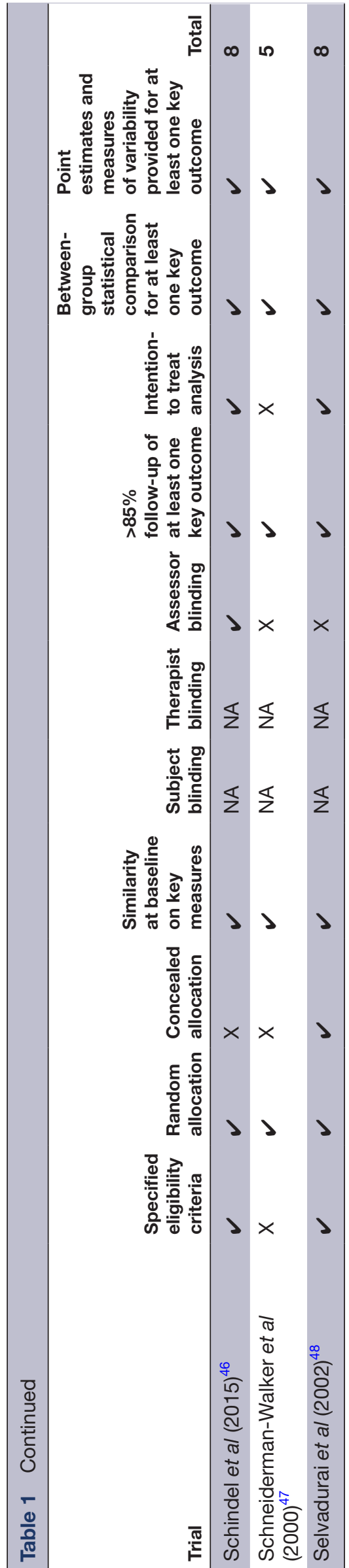

$30 \%^{313447}$ of the studies achieved a score of $\leq 5$. All studies were RCTs, but only five studies concealed their randomisation (three asthma, two CF). ${ }^{29} 36394248$ Assessor blinding was reported in 6 of the 27 studies. ${ }^{33} 36{ }^{39-46}$ For the majority of studies (25 out of 27) exercise and control groups exhibited similar baseline scores on primary outcomes $^{29} 3032-54$ and 22 out of 27 studies had less than $15 \%$ drop out. ${ }^{30313335-5254}$ All studies reported measures of variability and 26 out of the 27 studies described between group statistical comparisons. ${ }^{28-53}$ Intention-totreat analyses were conducted in 14 studies ( 8 out of 17 asthma, 6 out of $10 \mathrm{CF}) .^{29} 3135363841-46484952$

After excluding the three papers which were not eligible for the meta-analysis, 17 of 24 studies were found to have a moderate to high quality. ${ }^{29} 3335-4042-4648495152$ In asthma $67 \% 29333536404243495152$ and in CF $78 \%^{37-3944-4648}$ of the studies achieved a score of $\geq 6$. All studies were RCTs, five studies concealed their randomisation ${ }^{29} 36394248$ and assessor blinding was reported in six studies. $33363944-46$ Exercise and control groups exhibited similar baseline scores on primary outcomes in 22 studies. ${ }^{29} 3033$ 35-40 42-54 All studies reported measures of variability and 23 of the 24 studies described between group statistical comparisons. ${ }^{28-31} 33$ 35-40 42-53 From the 24 studies, 21 had less than $15 \%$ drop out $^{30313335-4042-5254}$ and 13 studies conducted intention to treat analyses. ${ }^{29} 3135363842-46484952$

\section{Types of exercise training}

The majority of exercise training programme were supervised in or out of hospital. ${ }^{28-36} 39-45$ 49-54 Homebased exercise programme were evaluated in five studies (CF). $.^{37} 3846-48$ and $81 \%$ of the exercise training programme were delivered as individual training sessions, ${ }^{28} 2931333436-3941-4850-54$ however, five studies, all in children with asthma, were conducted as group training programme. ${ }^{30} 32354049$ A variety of exercise modes were used. These included running, ${ }^{28} 2934$ cycling, ${ }^{31} 33$ swimming, ${ }^{41}{ }^{52-54}$ circuit training, ${ }^{35} 49$ a combination of aerobic training and strength training, ${ }^{36-38} 44-48$ balance and coordination, ${ }^{42} 50$ group exercises, ${ }^{37} 40{ }^{51}$ basketball, ${ }^{30}$ thai $\mathrm{chi}^{32}$ and running relays games. ${ }^{39}$ Studies in patients with CF were limited to running, ${ }^{34}$ cycling, ${ }^{31}$ any exercises that raised heart rate (HR) including ball games, skipping ropes, relays ${ }^{37-39} 44-48$ and strength training. ${ }^{36444548}$ The duration of training ranged from 13 days ${ }^{31}$ to 3 years, ${ }^{47}$ with the majority ${ }^{28-30} 32-343640-4549-54$ of training programme being delivered over a time period ranging from 6 and 16 weeks. For most studies, training frequency was two sessions ${ }^{31} 363839424349-515354$ or three sessions per week. ${ }^{28-30} 32-34374044-4752$ Exercise duration ranged between 10 and $90 \mathrm{~min}$ per session. The duration of exercise in children with asthma (50-60 min per session) was typically longer than the one reported for children with CF (20-30 min per session). Exercise intensity monitoring was reported in 12 studies (7 asthma, ${ }^{28} 2933364143525 \mathrm{CF}^{3444} 454748$ ). Eleven out of the 12 studies used HR monitoring to monitor exercise intensity, ${ }^{28} 2933364143-45474852$ and the remaining study 
used treadmill slope and velocity. ${ }^{34}$ To define the HR for the optimal training intensity 7 of 11 studies used a percentage of HR max or submaximal HR $(65 \%-$ $80 \%),{ }^{28293343474852} 2$ studies used the HR at ventilatory threshold, ${ }^{44} 45$ at lactate threshold ${ }^{41}$ and 1 at two-thirds of the difference between the anaerobic threshold and the respiratory compensation point. ${ }^{36}$

\section{Outcome measures and findings}

Across the 27 trials included in the qualitative synthesis, 12 different outcomes were assessed, including cardiovascular fitness, pulmonary function, respiratory muscle strength, QoL, muscular strength, inflammation parameters, anaerobic fitness, physical activity, psychosocial indices, asthma control, broncho-hyper-responsiveness (BHR) and posture. In this review, six of these outcomes (cardiovascular fitness, pulmonary function, respiratory muscle strength, QoL, strength and inflammation) were included in the qualitative synthesis and discussed in detail. The remaining outcomes were excluded because they were assessed in only a few studies. From the 27 studies included in the quantitative synthesis, 24 were included in the meta-analysis (15 asthma, ${ }^{28-30} 33353640424349-549$ $\mathrm{CF}^{3137-3944-48}$ ). Using these studies, there were sufficient data to conduct a meta-analysis on the following outcomes: cardiovascular fitness (peak $\mathrm{VO}_{2}$ ), lung function $\left(\mathrm{FEV}_{1} \%\right)$ and QoL (PAQLQ or CFQ).

\section{Cardiovascular fitness}

Cardiovascular fitness was assessed in 19 studies, 10 of those studies were in children with asthma ${ }^{28-30} 33353640414951$ and 9 in children with $\mathrm{CF}^{31} 3437-39444548 \mathrm{Peak}^{32} \mathrm{VO}_{2}$ was the most common measure of cardiovascular fitness and was used in four studies in children with asthma ${ }^{28} 333651$ and seven studies in children with CF. ${ }^{37-3944454748}$ Other measurements of cardiovascular fitness were the $6 \mathrm{~min}$ walk test, ${ }^{29}{ }^{40}$ PWC $170,{ }^{30}$ work capacity via cycle and swimming ergometer, ${ }^{3541} 9$ min run distance ${ }^{49}$ and the 3 min step test. ${ }^{34}$ Cardiovascular fitness significantly improved in 16 out of 19 studies (9 asthma, ${ }^{28-3033} 36404149$ $7 \mathrm{CF}^{31343739444548}$ ).

\section{Meta-analysis}

Eleven studies reported data for peak $\mathrm{VO}_{2}$, four in children with asthma 28333651 and seven in children with CF. $^{37-3944454748}$ Across all studies, the mean effect size was large (SMD $=1.16,95 \%$ CI 0.61 to 1.70$)$ and significant in favour of the intervention. Subgroup analyses showed a large and significant effect size favouring the intervention among children with asthma (SMD $=1.97,95 \%$ CI 0.61 to 3.32) and a medium but significant effect size in favour of the intervention among children with $\mathrm{CF}(\mathrm{SMD}=0.77$, $95 \%$ CI 0.25 to 1.29 ). The corresponding forest plot can be found in figure 2. There was no relationship between the SMD and the volume, intensity and duration of the exercise training programme $(r=0.02-0.10)$. See figures included in online supplementary file 2.

\section{Lung function}

Pulmonary function was assessed in 23 studies, with 13 studies in children with asthma $29303233354042434951-54$ and 10 studies in children with $\mathrm{CF}^{31}{ }^{34} 37-3944-48 \mathrm{FEV}_{1}$ was used in all 23 studies, ${ }^{28}$ 30-35 37-40 42-49 51-53 with 16 reporting per cent predicted values and four studies reporting absolute values (litres (L)). Forced vital capacity (FVC) was the second most evaluated outcome, reported in 17 studies (9 asthma, ${ }^{29} 3032354351-548 \mathrm{CF}^{31} 34$ 37-39 44-46). PEF was measured in eight studies $293032404251-53$ in children with asthma. Four studies assessed maximal inspiratory and expiratory pressure (two asthma, ${ }^{29}{ }^{54}$ two $\mathrm{CF}^{44}{ }^{45}$ ) as outcomes. Eight ${ }^{29-32} 40434852$ out of 23 studies reported improvements in lung function. Six of those studies

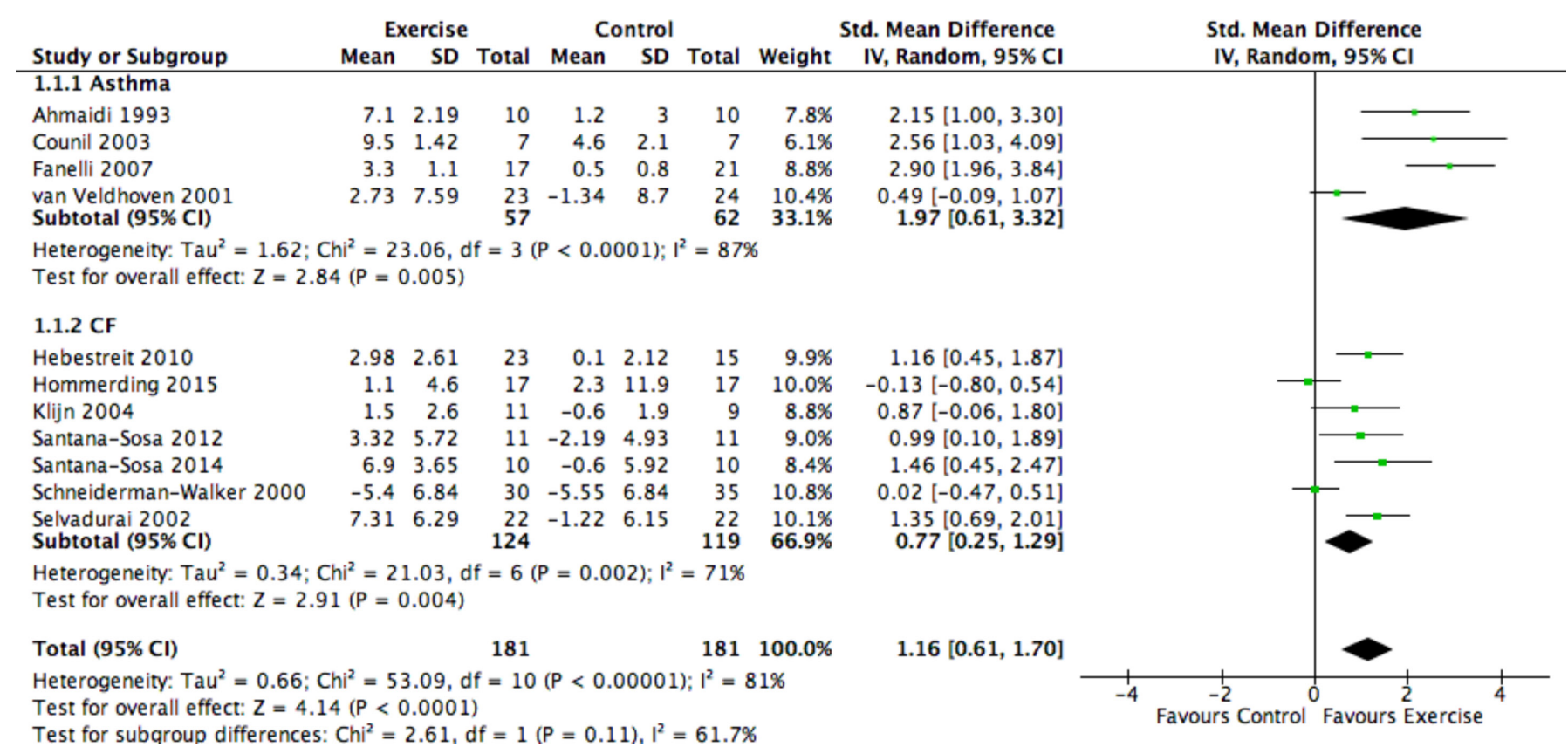

Figure 2 Forest plot: cardiovascular fitness $\left(\right.$ peak $\left.\mathrm{VO}_{2}\right)$. CF, cystic fibrosis. 


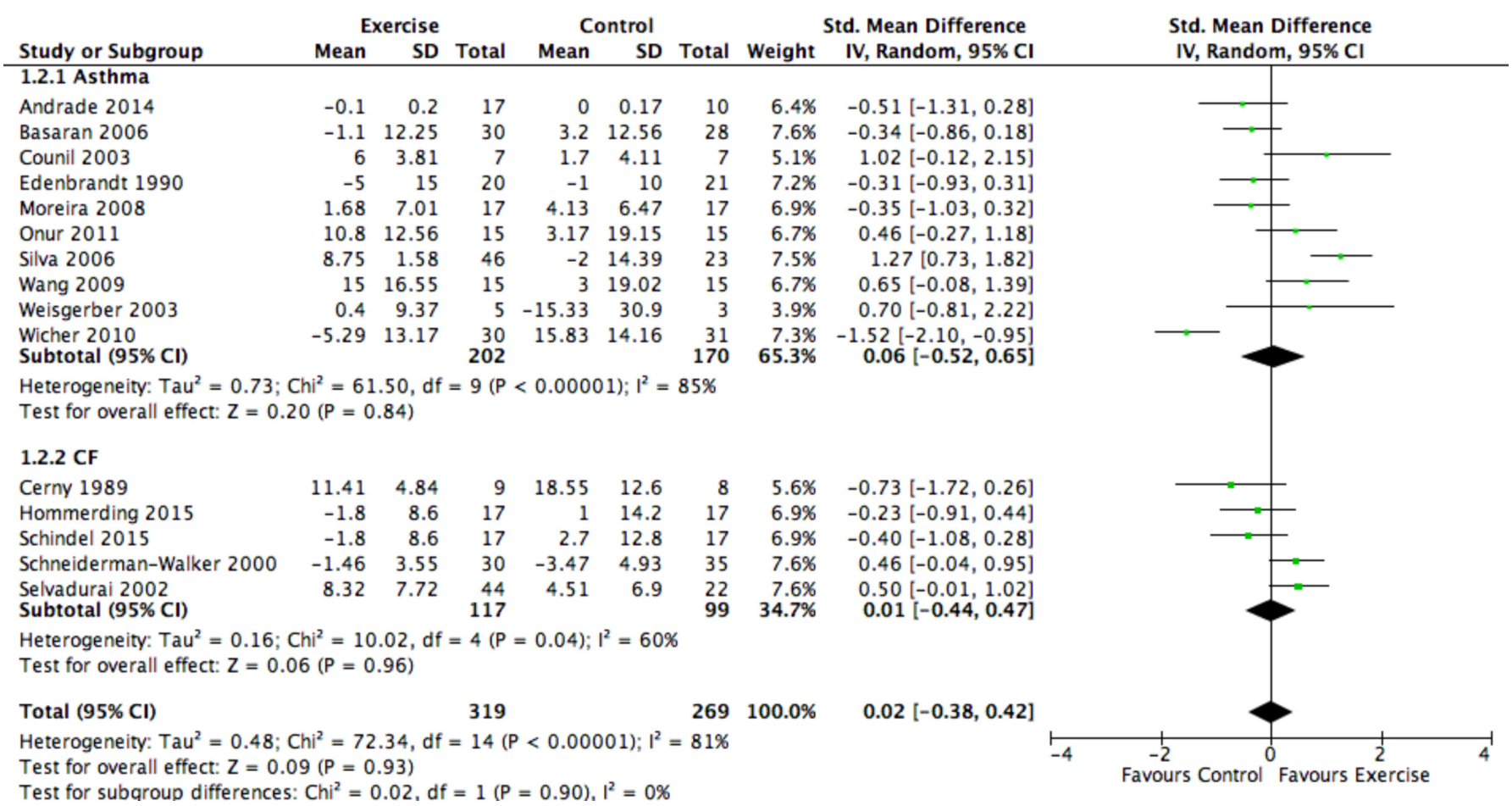

Figure 3 Forest plot: lung function $\left(\mathrm{FEV}_{1}\right)$. CF, cystic fibrosis.

reported a significant increase in $\mathrm{FEV}_{1}$ or FVC (four asthma, ${ }^{32404352}$ two $\mathrm{CF}^{3148}$ ) and five studies reported an increase in PEF. 2930324052

\section{Meta-analysis}

Fifteen studies reported changes in $\mathrm{FEV}_{1} \%$ predicted, 10 in children with asthma $2930333542434952-54$ and 5 in children with CF. ${ }^{31} 3846-48$ Across all studies, the mean effect size was small and non-significant $(\mathrm{SMD}=0.02,95 \% \mathrm{CI}$ 0.38 to 0.42 ). Effect sizes for change in $\mathrm{FEV}_{1}$ were similar for children with asthma $(\mathrm{SMD}=0.06,95 \% \mathrm{CI}-0.52$ to 0.65 ) and $\mathrm{CF}$ (SMD $=0.01,95 \% \mathrm{CI}-0.44$ to 0.47 ). The corresponding forest plot can be found in figure 3 .

\section{Quality of life}

QoL was assessed in 12 studies (6 asthma, ${ }^{29} 30364042506$ $\mathrm{CF}^{37-39} 444548$. All studies in children with asthma used the PAQLQ ${ }^{29} 3036404250$ In children with CF, the CFQ ${ }^{37-39}$ or CFQ Revised (CFQ-R) ${ }^{44} 45$ were used, with one exception (Quality of Wellbeing Scale). ${ }^{48}$ QoL improved in 8 out of 12 studies (4 in asthma, ${ }^{29} 3036404 \mathrm{CF}^{37394548}$ ). The four studies in asthma showed statistically significant improvement, ${ }^{29} 303640$ two studies in CF showed domain specific significant improvement, ${ }^{37}{ }^{39}$ one study in CF showed significant improvement in the aerobic exercise group but not in the resistance exercise groups ${ }^{48}$ and one study in CF had a borderline non-significant statistical improvement. ${ }^{45}$

\section{Meta-analysis}

The PAQLQ or the CFQ was used in eight studies, six in children with asthma ${ }^{29} 3036404250$ and two in children with $\mathrm{CF}^{44}{ }^{45}$ Across all studies, the mean effect size was large and significant ( $\mathrm{SMD}=1.27,95 \%$ CI 0.72 to 1.82 ) in favour of the intervention. Subgroup analyses revealed large and significant effect sizes in favour of the intervention in both children with asthma $(\mathrm{SMD}=1.33,95 \%$ CI 0.65 to 2.01) and children with $\mathrm{CF}$ (SMD $=1.10,95 \%$ CI 0.16 to 2.04). The corresponding forest plot can be found in figure 4 . There was no correlation between the SMD and the volume, intensity and duration of the exercise training programme $(\mathrm{r}=-0.5$ to 0.06$)$ (online supplementary file 2 ).

\section{Muscular strength}

Muscular strength was measured in six studies (two asthma, ${ }^{40}{ }^{49}$ four $\mathrm{CF}^{39444548}$ ), using a variety of protocols and indices including grip strength, ${ }^{40}$ countermovement jumps, ${ }^{40}$ number of sit ups, ${ }^{49}$ isometric muscle force, ${ }^{39}$ maximum weight for five repetitions (five RM) for bench press, leg press and seated row ${ }^{445}$ and isokinetic muscle strength of the quadriceps and hamstring. ${ }^{48}$ Five studies (two asthma, ${ }^{40} 49$ three $\mathrm{CF}^{44} 4548$ ) reported significant increases in muscular strength by measuring grip strength ${ }^{40}$ countermovement jumps, ${ }^{40}$ number of sit-ups, ${ }^{49}$ maximum weight for five repetitions (five RM) for bench press, leg press and seated row ${ }^{44}$ or isokinetic muscle strength of the quadriceps and hamstring. ${ }^{48}$ Of note, four additional studies assessed respiratory muscle strength (two asthma, ${ }^{29} 54$ two $\mathrm{CF}^{44} 45$ ), by determining maximal inspiratory and/or expiratory pressure. Respiratory muscle strength improved significantly in three out of the four studies (two asthma, ${ }^{2954}$ one $\mathrm{CF}^{45}$ ).

\section{Inflammation}

Inflammatory markers were measured in four studies (three asthma, ${ }^{294243}$ one $\mathrm{CF}^{34}$ ). C reactive protein ${ }^{3442}$ was 


\begin{tabular}{|c|c|c|c|c|c|c|c|}
\hline \multirow[b]{2}{*}{ Study or Subgroup } & \multicolumn{3}{|c|}{ Exercise } & \multicolumn{3}{|c|}{ Control } & \multirow[b]{2}{*}{ Weight } \\
\hline & Mean & SD & Total & Mean & SD & Total & \\
\hline \multicolumn{8}{|l|}{ 1.3.1 Asthma } \\
\hline Andrade 2014 & 1.2 & 0.36 & 17 & -0.1 & 0.26 & 10 & $16.4 \%$ \\
\hline Basaran 2006 & 1.2 & 0.61 & 30 & 0.42 & 0.8 & 28 & \\
\hline Fanelli 2007 & 2.15 & 1.65 & 17 & 0.6 & 1.45 & 21 & $22.0 \%$ \\
\hline Latorre-Roman 2014 & 2.51 & 1.39 & 58 & -0.17 & 1.55 & 47 & \\
\hline Moreira 2008 & 0.61 & 0.49 & 17 & 0.45 & 0.62 & 17 & $22.0 \%$ \\
\hline $\begin{array}{l}\text { Silva } 2013 \\
\text { Subtotal }(95 \% \mathrm{CI})\end{array}$ & 0.8 & 0.78 & $\begin{array}{l}15 \\
51\end{array}$ & 0.1 & 0.97 & $\begin{array}{l}15 \\
48\end{array}$ & $60.4 \%$ \\
\hline \multicolumn{8}{|c|}{$\begin{array}{l}\text { Heterogeneity: } \mathrm{Tau}^{2}=1.73 ; \mathrm{Chi}^{2}=21.27, \mathrm{df}=2(\mathrm{P}<0.0001) ; \mathrm{I}^{2}=91 \% \\
\text { Test for overall effect: } \mathrm{Z}=1.96(P=0.05)\end{array}$} \\
\hline \multicolumn{8}{|l|}{$1.3 .2 \mathrm{CF}$} \\
\hline Santana-Sosa 2012 & 23.5 & 67.64 & 11 & -29 & 82.91 & 11 & $20.6 \%$ \\
\hline $\begin{array}{l}\text { Santana-Sosa } 2014 \\
\text { Subtotal }(95 \% \mathrm{CI})\end{array}$ & 78 & 55 & $\begin{array}{l}10 \\
21\end{array}$ & -1 & 35.89 & $\begin{array}{l}10 \\
21\end{array}$ & $\begin{array}{l}19.0 \% \\
39.6 \%\end{array}$ \\
\hline \multicolumn{8}{|c|}{$\begin{array}{l}\text { Heterogeneity: } \mathrm{Tau}^{2}=0.22 ; \mathrm{Ch}^{2}=1.94, \mathrm{df}=1(\mathrm{P}=0.16) ; \mathrm{I}^{2}=48 \% \\
\text { Test for overall effect: } \mathrm{Z}=2.30(\mathrm{P}=0.02)\end{array}$} \\
\hline Total $(95 \% \mathrm{Cl})$ & & & 72 & & & 69 & $100.0 \%$ \\
\hline \multicolumn{8}{|c|}{$\begin{array}{l}\text { Heterogeneity: } \mathrm{Tau}^{2}=0.92 ; \mathrm{Chi}^{2}=23.24, \mathrm{df}=4(P=0.0001) ; \mathrm{I}^{2}=83 \% \\
\text { Test for overall effect: } \mathrm{Z}=2.83(P=0.005) \\
\text { Test for subaroup differences: } \mathrm{Chi}^{2}=0.26 . \mathrm{df}=1(\mathrm{P}=0.61) . \mathrm{I}^{2}=0 \%\end{array}$} \\
\hline
\end{tabular}

Figure 4 Forrest plot: quality of life.

the most common blood parameter assessed and fractional exhaled nitric oxide (FeNO) ${ }^{42}{ }^{43}$ the most common asthma biomarker. Other parameters were plasma cytokines,${ }^{29}$ immunoglobulin E (IgE),${ }^{42}$ malondialdehyde, ${ }^{43}$ glutathione peroxidase (GSH-Px $)^{43}$ and superoxide dismutase. ${ }^{43}$ An improvement in inflammation was found in two ${ }^{42} 43$ of the three studies in children with asthma, which was shown by a statistically significant decrease in $\mathrm{FeNO}^{43}$ and mite-specific $\mathrm{IgE}^{42}$ and significant increase in GSH-Px. ${ }^{43}$

\section{DISCUSSION}

The aim of this systematic review and meta-analysis was to synthesise the available research investigating the effects of exercise training in children with respiratory disease related to asthma, CF, bronchiectasis or BPD. A total of 27 RCT's were included in the systematic review; 17 were on children with asthma and 10 studies involved children with CF. Eighteen of those studies were moderate to high quality. Importantly, no exercise training studies involving children and adolescents with bronchiectasis (or PCD) or BPD were identified. From these 27 studies, 24 were included in the meta-analysis. A large significant mean effect size in favour of exercise was found for cardiovascular fitness $\left(\mathrm{VO}_{2}\right.$ peak) $(\mathrm{SMD}=1.16,95 \% \mathrm{CI}$ 0.61 to 1.70 ) and QoL (SMD=1.27, $95 \%$ CI 0.72 to 1.82 ) as well as a small, non-significant mean effect size in lung function.

A key finding from the present review was the absence of studies evaluating exercise training in children with respiratory diseases other than asthma or CF. Although clinical guidelines for the treatment and management of respiratory disease recommend exercise ${ }^{55}$ the results highlight the need for exercise training studies for other respiratory conditions, such as bronchiectasis and BPD. Further research is needed to determine if exercise training is equally beneficial for children with
Std. Mean Difference

IV, Random, $95 \% \mathrm{CI}$

$3.85[2.49,5.21]$

Not estimable

$0.98[0.30,1.66]$

Not estimable

$0.28[-0.40,0.96]$

Not estimable

$1.58[-0.00,3.16]$
$0.67[-0.20,1.53]$
$1.63[0.59,2.67]$
$1.10[0.16,2.04]$

$1.36[0.42,2.30]$

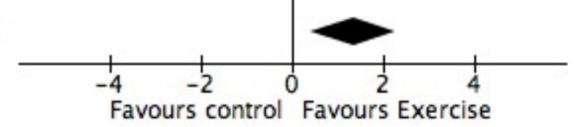

Std. Mean Difference IV, Random, $95 \% \mathrm{Cl}$

bronchiectasis, BPD or other respiratory conditions and whether generalised clinical guidelines for therapeutic exercise in children with respiratory disease are justified.

In studies investigating children with asthma and CF, there was considerable heterogeneity with respect to the mode, frequency, intensity and duration of exercise training. Frequency ranged from 1 to 7 sessions per week, duration from 13 days to 3 years and the length of training ranged from 10 to $90 \mathrm{~min}$ per session. The majority were individually supervised sessions. The mode ranged from single exercise modes such as running or cycling to ball games, strength training and coordination. Some studies offered strictly just one mode, while others combined different modes and some studies offered a wide variety of modes from which the patient could choose the most favourable for him or her. The majority of sessions were prescribed with little to no consideration for motivational strategies appropriate for children, such as games. Even though studies meeting the inclusion criteria consistently reported significant improvements in cardiovascular fitness and QoL, no relationship between intensity, duration and volume of exercise training was observed. The reasons for this may be the small number of studies included in this analysis, the wide range of exercise mode and inconsistency in frequency, duration and intensity.

Across studies, there was little consistency in the primary outcomes and the methods used to assess the outcomes, making it difficult to combine results in the meta-analyses and to draw conclusions. For example, five different measurement protocols were used to assess cardiovascular fitness, resulting in five different metrics. Due to this lack of consistency, it was not possible to include all RCTs investigating cardiovascular fitness in the meta-analysis. It would be preferable for the field to adopt a consensus approach in relation to the preferred metrics and measurement protocols for assessing cardiovascular fitness and other health outcomes in children 
with respiratory disease. This would improve comparability between studies and strengthen the conclusions of future systematic reviews.

Muscular strength and endurance are important outcomes of exercise training as they facilitate physical function and improve QoL. ${ }^{56}$ Six studies that evaluated muscular strength were included, but because different outcomes were measured, it was not possible to include them in the meta-analysis. An earlier review of exercise training studies conducted in patients with CF concluded that significant improvements in strength can be achieved through regular exercise training. ${ }^{21}$ The conclusions of our qualitative synthesis are in agreement with this finding.

There is growing evidence that exercise has a positive effect on inflammation. ${ }^{57-59}$ Inflammation is a major contributor to disease in respiratory diseases. In patients with $\mathrm{CF}$, it leads to damage of lung tissue resulting in higher susceptibility for new infections. ${ }^{60}$ In asthma, ongoing inflammation is associated with poorer clinical outcomes. ${ }^{61}$ Therefore, investigating the effect of exercise on inflammatory parameters in children with respiratory disease is an important area of research. The effect of exercise on inflammation was investigated in only three studies, and although two reported an improvement, it is not possible to draw a reliable conclusion for this outcome. Studies differed in duration, mode and frequency and examined different inflammatory markers. Studies are needed investigating the same inflammatory markers making it possible to combine studies and to draw reliable conclusions on whether exercise has an anti-inflammatory effect.

In summary, the results of this systematic review and meta-analysis provide evidence that therapeutic exercise significantly improves cardiovascular fitness and QoL in children with respiratory disease related to asthma or CF. A comparison of effect sizes for patients with asthma and $\mathrm{CF}$ indicates that exercise has a larger effect on cardiovascular fitness for asthma than $\mathrm{CF}$ and a similar large effect on QoL for both disease groups. No correlation was observed between the magnitude of improvement and the dose of training suggesting that more research is needed to determine the optimal frequency, intensity and duration of exercise training in this patient group. In particular, future studies should evaluate the health impacts of exercise training in children with respiratory conditions other than asthma and CF, such as bronchiectasis and BPD.

\footnotetext{
Author affiliations

${ }^{1}$ School of Human Movement and Nutrition Sciences, The University of Queensland, Brisbane, Queensland, Australia

${ }^{2}$ School of Health \& Rehabilitation Sciences, The University of Queensland, Brisbane, Queensland, Australia

${ }^{3}$ School of Nursing and Midwifery, Griffith University, Brisbane, Queensland, Australia

${ }^{4}$ Child Health Division, Menzies School of Health Research, Charles Darwin University, Tiwi, Australia
}

${ }^{5}$ Institute of Health and Biomedical Innovation, Centre for Children's Health Research, Queensland University of Technology, Brisbane, Queensland, Australia ${ }^{6}$ Department of Respiratory Medicine, Lady Cilento Children's Hospital, Children's Health Queensland, Brisbane, Queensland, Australia

Contributors BJ devised the research question, completed the search, screened papers, extracted and analysed data and wrote the paper. ST was a major contributor in designing the research question, screening papers, analysing data and writing the paper. SRG contributed to the quality assessment and writing the paper. HP assisted in devising the research question and writing the paper. SGT and $\mathrm{ABC}$ contributed to manuscript development. All authors read and approved the final manuscript.

Funding Professor Chang is supported by an Australian National Health and Medical Research Council (NHMRC) Practitioner Fellowship (Grant APP1058213).

Competing interests None declared.

Patient consent Not required.

Provenance and peer review Not commissioned; externally peer reviewed.

Data sharing statement Data are available from the corresponding author on request s.trost@qut.edu.au.

Open access This is an open access article distributed in accordance with the Creative Commons Attribution Non Commercial (CC BY-NC 4.0) license, which permits others to distribute, remix, adapt, build upon this work non-commercially, and license their derivative works on different terms, provided the original work is properly cited, appropriate credit is given, any changes made indicated, and the use is non-commercial. See: http://creativecommons.org/licenses/by-nc/4.0/

\section{REFERENCES}

1. AlHW. Australia's health 2016. Canberra: Australian Institute of Health and Welfare, 2016.

2. WHO. Global Status Report on noncommunicable diseases. Switzerland: World Health Organization, 2014.

3. Van Cleave J, Gortmaker SL, Perrin JM. Dynamics of obesity and chronic health conditions among children and youth. JAMA 2010;303:623-30.

4. Michaud P-A, Suris JC, Viner R. The Adolescent with a chronic condition:epidemiology, developmental issues and health care provision. Geneva, Swizerland: WHO, 2007.

5. ABS. National Health Survey: First Results 2014-2015. Canberra: Australien Bureau of Statistics, 2015.

6. Lissauer T, Clayden G. Illustrated textbook of paediatrics. 3 edn. Muenchen, Germany: Elsevier Urban\&Fischer:, 2007.

7. Schraufnagel D. Breathing in America: disease, progress, and hope. Amarican Thoracic Society, 2010.

8. British Thoracic SocietyScottish Intercollegiate Guidelines Network. British guideline on the management of asthma. Thorax 2003;58:1-94.

9. Global Initiative for Asthma, 2018. www.ginaasthma.org

10. O'Donnell AE. Bronchiectasis. Chest 2008:134:815-23.

11. Goyal V, Grimwood K, Marchant J, et al. Pediatric bronchiectasis: no longer an orphan disease. Pediatr Pulmonol 2016;51:450-69.

12. Stoll BJ, Hansen NI, Bell EF, et al. Trends in care practices, morbidity, and mortality of extremely preterm neonates, 1993-2012. JAMA 2015;314:1039-51.

13. O'Reilly M, Sozo F, Harding R. Impact of preterm birth and bronchopulmonary dysplasia on the developing lung: long-term consequences for respiratory health. Clin Exp Pharmacol Physiol 2013;40:765-73.

14. Janssen I, Leblanc AG. Systematic review of the health benefits of physical activity and fitness in school-aged children and youth. Int $J$ Behav Nutr Phys Act 2010;7:40.

15. Okely T, Salmon J, Vella S, et al. A systematic review to update the Australian physical activity guidelines for children and young people. Report prepared for the Australian Government Department of Health 2013.

16. Pieles GE, Horn R, Williams CA, et al. Paediatric exercise training in prevention and treatment. Arch Dis Child 2014;99:380-5.

17. Beggs S, Foong YC, HC L, et al. Swimming training for asthma in children and adolescents aged 18 years and under. The Cochrane Database Syst Rev 2013;4:CD009607.

18. Crosbie A. The effect of physical training in children with asthma on pulmonary function, aerobic capacity and health-related quality of life: a systematic review of randomized control trials. Pediatr Exerc Sci 2012;24:472-89. 
19. Wanrooij VH, Willeboordse M, Dompeling E, et al. Exercise training in children with asthma: a systematic review. Br J Sports Med 2014;48:1024-31.

20. Welsh L, Kemp JG, Roberts RG. Effects of physical conditioning on children and adolescents with asthma. Sports Med 2005;35:127-41.

21. van Doorn N. Exercise programs for children with cystic fibrosis: a systematic review of randomized controlled trials. Disabil Rehabil 2010;32:41-9.

22. Carson KV, Chandratilleke MG, Picot J. Physical training for asthma. Cochrane Database Syst Rev 2013;9:CD001116.

23. Radtke T, Nevitt SJ, Hebestreit $\mathrm{H}$, et al. Physical exercise training for cystic fibrosis. Cochrane Database Syst Rev 2017;11:CD002768.

24. Higgins JP, Green S. Cochrane handbook for systematic reviews of interventions. John Wiley \& Sons: Hoboken NJ, 2011.

25. Moher D, Liberati A, Tetzlaff J, et al. Preferred reporting items for systematic reviews and meta-analyses: the PRISMA statement. $J$ Clin Epidemiol 2009;62:1006-12.

26. Verhagen AP, de Vet HC, de Bie RA, et al. The Delphi list: a criteria list for quality assessment of randomized clinical trials for conducting systematic reviews developed by Delphi consensus. J Clin Epidemiol 1998;51:1235-41.

27. Moseley AM, Herbert RD, Sherrington C, et al. Evidence for physiotherapy practice: a survey of the Physiotherapy Evidence Database (PEDro). Aust J Physiother 2002;48:43-9.

28. Ahmaidi SB, Varray AL, Savy-Pacaux AM, et al. Cardiorespiratory fitness evaluation by the shuttle test in asthmatic subjects during aerobic training. Chest 1993;103:1135-41.

29. Andrade LB, Britto MC, Lucena-Silva N, et al. The efficacy of aerobic training in improving the inflammatory component of asthmatic children. Randomized trial. Respir Med 2014;108:1438-45.

30. Basaran S, Guler-Uysal F, Ergen N, et al. Effects of physical exercise on quality of life, exercise capacity and pulmonary function in children with asthma. J Rehabil Med 2006;38:130-5.

31. Cerny FJ. Relative effects of bronchial drainage and exercise for in-hospital care of patients with cystic fibrosis. Phys Ther 1989;69:633-9.

32. Chang YF, Yang YH, Chen CC, et al. Tai Chi Chuan training improves the pulmonary function of asthmatic children. J Microbiol Immunol Infect 2008;41:88-95

33. Counil FP, Varray A, Matecki S, et al. Training of aerobic and anaerobic fitness in children with asthma. $J$ Pediatr 2003:142:179-84.

34. de Oliveira ACN, de Oliveira JCM, Mesquita-Ferrari RA. Inflammatory process modulation in children with cystic fibrosis submitted to aerobic training. Arch Med Sci 2009;5:422-6.

35. Edenbrandt L, Olséni L, Svenonius E, et al. Effect of physiotherapy in asthmatic children--a one-year follow-up after physical training once a week. Acta Paediatr Scand 1990;79:973-5.

36. Fanelli A, Cabral AL, Neder JA, et al. Exercise training on disease control and quality of life in asthmatic children. Med Sci Sports Exerc 2007;39:1474-80.

37. Hebestreit H, Kieser S, Junge S, et al. Long-term effects of a partially supervised conditioning programme in cystic fibrosis. Eur Respir J 2010;35:578-83.

38. Hommerding PX, Baptista RR, Makarewicz GT, et al. Effects of an educational intervention of physical activity for children and adolescents with cystic fibrosis: a randomized controlled trial. Respir Care 2015;60:81-7.

39. Klijn PH, Oudshoorn A, van der Ent CK, et al. Effects of anaerobic training in children with cystic fibrosis: a randomized controlled study. Chest 2004:125:1299-305.

40. Latorre-Román PÁ, Navarro-Martínez AV, García-Pinillos F. The effectiveness of an indoor intermittent training program for improving lung function, physical capacity, body composition and quality of life in children with asthma. J Asthma 2014;51:544-51.
41. Matsumoto I, Araki H, Tsuda K, et al. Effects of swimming training on aerobic capacity and exercise induced bronchoconstriction in children with bronchial asthma. Thorax 1999;54:196-201.

42. Moreira A, Delgado L, Haahtela T, et al. Physical training does not increase allergic inflammation in asthmatic children. Eur Respir $J$ 2008;32:1570-5

43. Onur E, Kabaroğlu C, Günay $O$, et al. The beneficial effects of physical exercise on antioxidant status in asthmatic children. Allergol Immunopathol 2011;39:90-5.

44. Santana Sosa E, Groeneveld IF, Gonzalez-Saiz L, et al. Intrahospital weight and aerobic training in children with cystic fibrosis: a randomized controlled trial. Med Sci Sports Exerc 2012;44:2-11.

45. Santana-Sosa E, Gonzalez-Saiz L, Groeneveld IF, et al. Benefits of combining inspiratory muscle with 'whole muscle' training in children with cystic fibrosis: a randomised controlled trial. Br J Sports Med 2014;48:1513-7.

46. Schindel CS, Hommerding PX, Melo DA, et al. Physical exercise recommendations improve postural changes found in children and adolescents with cystic fibrosis: a randomized controlled trial. $J$ Pediatr 2015;166:710-6.

47. Schneiderman-Walker J, Pollock SL, Corey M, et al. A randomized controlled trial of a 3-year home exercise program in cystic fibrosis. J Pediatr 2000;136:304-10.

48. Selvadurai HC, Blimkie CJ, Meyers N, et al. Randomized controlled study of in-hospital exercise training programs in children with cystic fibrosis. Pediatr Pulmonol 2002;33:194-200.

49. Silva CS, Torres LA, Rahal A, et al. Comparison of morning and afternoon exercise training for asthmatic children. Braz J Med Biol Res 2006;39:71-8.

50. Silva D, Couto M, Moreira $\mathrm{P}$, et al. Physical training improves quality of life both in asthmatic children and their caregivers. Ann Allergy Asthma Immunol 2013;111:427-8.

51. van Veldhoven $\mathrm{NH}$, Vermeer A, Bogaard JM, et al. Children with asthma and physical exercise: effects of an exercise programme. Clin Rehabil 2001;15:360-70.

52. Wang JS, Hung WP. The effects of a swimming intervention for children with asthma. Respirology 2009;14:838-42.

53. Weisgerber MC, Guill M, Weisgerber JM, et al. Benefits of swimming in asthma: effect of a session of swimming lessons on symptoms and PFTs with review of the literature. J Asthma 2003;40:453-64.

54. Wicher IB, Ribeiro MA, Marmo DB, et al. Effects of swimming on spirometric parameters and bronchial hyperresponsiveness in children and adolescents with moderate persistent atopic asthma. $J$ Pediatr 2010;86:384-90.

55. Chang AB, Bell SC, Torzillo PJ, et al. Chronic suppurative lung disease and bronchiectasis in children and adults in Australia and New Zealand Thoracic Society of Australia and New Zealand guidelines. Med J Aust 2015;202:130-23.

56. American College of Sports Medicine. ACSM's guidelines for exercise testing and prescription. Philadephia,PE: Lippincott Williams \& Wilkins, 2013.

57. Horsburgh S, Robson-Ansley P, Adams R, et al. Exercise and inflammation-related epigenetic modifications: focus on DNA methylation. Exerc Immunol Rev 2015;21:26-41.

58. Krüger K, Mooren FC, Pilat C. The immunomodulatory effects of physical activity. Curr Pharm Des 2016;22:3730-48.

59. Richter MJ, Grimminger J, Krüger B, et al. Effects of exercise training on pulmonary hemodynamics, functional capacity and inflammation in pulmonary hypertension. Pulm Circ 2017;7:20-37.

60. Elizur A, Cannon CL, Ferkol TW. Airway inflammation in cystic fibrosis. Chest 2008;133:489-95.

61. Murdoch JR, Lloyd CM. Chronic inflammation and asthma. Mutat Res 2010;690:24-39. 